\title{
Manyetik rezonans görüntüleme yapılan pediatrik olgularda midazolam-ketamin kombinasyonu ile tiopentalin sedatif etkilerinin karşılaştırılması
}

\author{
Oylum Selçuk ${ }^{1}$, Ayşe Hancı², Enis Selçuk¹, Hacer Şebnem Türk², Barış Türk³, Güneri Atalan²
}

\begin{abstract}
ÖZET:
Manyetik rezonans görüntüleme yapılan pediatrik olgularda midazolam-ketamin kombinasyonu ile tiopental'in sedatif etkilerinin karşılaştırılması

Giriş ve Amaç: Manyetik rezonans görüntüleme (MRG)'de gürültü varlığı, işlem sırasında hareketsizliğin gerekmesi, dar alana girme zorluğu, özellikle 8 yaş altı çocuklarda sedasyon uygulamasını gerekli kılmaktadır. Çalışmamızda, MRG yapılan çocuklarda tiyopental ve midozolam-ketamin sedasyonunu karşılaştırmayı amaçladık.

Gereç ve Yöntem: Etik kurul onayı alındıktan sonra, MRG yapılan, 0-8 yaş arası, ASA I-II 40 olgu rastgele çalışmaya dahil edildi. Grup 1'e Midazolam iv $0.1 \mathrm{mg} / \mathrm{kg}+$ Ketamin iv $2 \mathrm{mg} / \mathrm{kg}$ indüksiyon dozunun ardından, idamede ek doz ketamin $0.5 \mathrm{mg} / \mathrm{kg}$ uygulandı. Grup 2'ye Tiopental iv $3 \mathrm{mg} / \mathrm{kg}$ indüksiyon dozunun ardından, idamede gereğinde ek doz $1 \mathrm{mg} / \mathrm{kg}$ tiyopental uygulandı. Sedasyon düzeyini belirlemede University of Michigan Sedation Scale (UMSS) kullanıldı. UMSS 3 ve üzeri olması yeterli sedasyon düzeyi olarak kabul edilip hastalar, MRG'ye verildi. Demografik veriler, indüksiyon, işlem, derlenme ve toplam sedasyon süreleri, MRG kalitesi, toplam anestezik ilaç miktarı, başlangıçtan itibaren her 5 dakikada bir sistolik ve diyastolik arter basıncı, kalp tepe atımı ve satürasyon değerleri, komplikasyonlar kaydedildi.

Bulgular: Grupların yaş ve ağırlık dağılımları arasında istatistiksel olarak anlamlı fark bulunmamıştır. Grup 1 'in indüksiyon süreleri, toplam sedasyon süreleri ve derlenme süreleri ortalamaları Grup 2'den istatiksel olarak anlamlı oranda uzundur ( $p=0,001, p=0,035, p=0,038)$. Her iki grup karşılaş̧ırıılığında KTA, SKB, DKB ve SpO2 dağılımları arasında tüm zamanlarda istatiksel anlamlı farklııı tespit edilmemiştir. Aile memnuniyeti açısından değerlendirildiğinde, midazolam -ketamin grubunda 19 kişi çok memnun, 1 kişi ortaderece memnun olarak, tiyopental uygulanan grupta ise 18 kişi çok memnun, 2 kişi orta derecede memnun olarak belirtti. Çekim kalitisinin değerlendirilmesinde de gruplar arasında anlamlı farklılık tespit edilmemiştir. Grupların ikisinde de yan etki ile karşılaşılmamıştır.

Sonuç: Tiyopental MRG'de midozolam ve ketamin kombinasyonuna alternatif olarak güvenle kullanılabilir. Çekim kalitesinin iyi olması, anestezi indüksiyon süresi ve derlenme süresinin kısa olması, tiyopentali MRG'de daha etkin bir anestezik ajan haline getirmektedir.

Anahtar kelimeler: Manyetik rezonans görüntüleme, midozolam, ketamin, tiyopental
\end{abstract}

\section{ABSTRACT:}

Comparison of sedative effects of midazolam-ketamine combination and thiopental in pediatric patients undergoing magnetic resonance imaging

Introduction and Aim: Children especially under age 8 cannot lie still enough for magnetic resonance imaging (MRI) or are afraid of noise and narrow spaces so sedation is necessary for high quality imaging. The aim of this study was to compare Midazolam - Ketamine combination and Thiopental sedation for children undergoing MRI.

Materials and Methods: Forty randomly selected patients undergoing MRI classified as ASA physical status I and II aged between 0-8 were included in this study after receiving institutional approval from Ethics Committee. The patients were divided into two groups. Group 1 received Midazolam iv $0.1 \mathrm{mg} \mathrm{kg}+$ Ketamine iv $2 \mathrm{mg} \mathrm{kg}$ followed by an additional dose of Ketamine $0.5 \mathrm{mg} \mathrm{kg}$. Group 2 received Thiopental iv $3 \mathrm{mg}$ $\mathrm{kg}$ followed by an additional dose of Thiopental $1 \mathrm{mg} \mathrm{kg}$ when needed. University of Michigan Sedation Scale (UMSS) was applied. UMSS score 3 and higher were accepted for effective sedation and the patients underwent MRI. Demographic data induction process recovery and total sedation times MRI quality total anesthetic dose amount systolic and diastolic blood pressure at every 5 minutes from the beginning peak heart rate and saturation values and complications were recorded.

Results: There was no significant difference in terms of age and weight between the two groups. The average induction time total sedation time and recovery time of Group 1 was significantly longer than that of Group 2 $(p=0.001, p=0.035, p=0.038)$. There were no significant differences in PHR SBP DBP and SpO2 distributions at all times. Evaluations of the families of Midazolam - Ketamine group's patients were recorded as 19 very satisfied 1 satisfied while evaluations of the families of Thiopental group's patients were recorded as 18 very satisfied 2 satisfied. There was no significant difference between the two groups in terms of imaging quality. No side effects or complications were observed for both groups.

Discussion: Thiopental was found to be a safe alternative to Midozolam - Ketamine combination in MRI. High image quality anesthesia induction time and short recovery time make Thiopental a more effective anesthetic agent for MRI.

Key words: Magnetic resonance imaging, midozolam, ketamine, thiopenthal

Ş.E.E.A.H. Tıp Bülteni 2013;47(3):122-129
'Sinop Devlet Hastanesi Anesteziyoloji ve Reanimasyon, Sinop-Türkiye

${ }^{2}$ Şişli Etfal Eğitim ve Araştırma Hastanesi Anesteziyoloji ve Reanimasyon Kliniği, Istanbul-Türkiye

${ }^{3}$ Kağıthane Devlet Hastanesi Radyoloji, İstanbul-Türkiye

Yazışma Adresi / Address reprint requests to: Hacer Şebnem Türk, Şişli Etfal Eğitim ve Araştırma Hastanesi, 1. Anesteziyoloji ve Reanimasyon Kliniği, i̇stanbul-Türkiye

Telefon / Phone: +90-231-2209/5414

E-posta / E-mail:

hacersebnem@yahoo.com.tr

Geliş tarihi / Date of receipt: 7 Nisan 2013 / April 7, 2013

Kabul tarihi / Date of acceptance: 5 Eylül 2013 / September 5, 2013 


\section{Gíriş}

Manyetik rezonans görüntüleme (MRG) ünitesi anestezist için ortamdan, hastadan ve işlemden kaynaklanan farklı özellikler taşıyan ve yüksek görüntü kalitesi nedeniyle klinik uygulamalarda giderek daha fazla yer bulan bir görüntüleme yöntemidir (1). Şiddetli gürültü varlığı, iyi görüntü sağlanabilmesi için bu işlem sırasında tam bir hareketsizliğin gerekmesi ve kapalı alana girme zorunluluğu özellikle çocuklarda ve hareketsiz kalamayan, zihinsel özürlü ya da kapalı alan korkusu olan erişkinlerde sedasyon veya genel anestezi uygulamalarını gerekli kılmaktadır (2).

MRG'de uygulanan anestezi şekli günübirlik anestezi olarak adlandırılır.Günübirlik anestezi hastanın işleminin yapıldığı gün hastanede tutulmadan evine gönderilmesini mümkün kılan ve günümüzde bazı cerrahi girişimlerde özellikle tercih edilen bir anestezi yöntemidir.Günübirlik anestezide kullanılan ajanlarla yapılan anestezi indüksiyonunda hastanın çabuk uyuması, idamesinde vital fonksiyonlarını stabil olmaSı, anestezi sonrası hastanın çabuk uyanması, hızlı derlenme, derlenme sonrası fizik ve mental aktivitelerinin en kısa sürede normale dönmesi ve taburculuğunu geciktirecek bulantı, kusma, baş dönmesi ve ağrı gibi yan etkilerin olmaması gereklidir (3).

Ketamin amnezi ve analjezi etkisi olan bir ajandır. Solunum fonksiyonu ve kardiyovasküler fonksiyonlarda önemli bir yan etkisi görülmemektedir (4). Ancak, uyanma sırasında halüsinasyon ve bulantı gibi istenmeyen yan etkisi bulunmaktadır (5). Tiyopental sodyum (pentotal), kısa etki süreli bir barbitürat olup pediatrik hastaların sedasyonunda güvenliği ve etkinliği kanıtlanmıştır (6).

Biz bu çalışmada Manyetik rezonans görüntüleme tetkiki için anestezi uygulanacak pediatrik olgularda midazolam-ketamin kombinasyonu ile tiopentalin anestezi kalitesi, girişim sırasındaki konfor ve derlenme üzerine etkilerinin karşılaştırılmasını amaçladık.

\section{GEREÇ VE YÖNTEM}

Etik kurul onayı alındıktan sonra, Şişli Etfal Eğitim ve Araştırma Hastanesinde çeşitli nedenlerle manyetik rezonans görüntüleme yapılacak ASA I-II, 0-8 yaş arası 40 olgu çalışmamıza dahil edildi. Çalışmamız, pros- pektif, kontrollü ve randomize olarak planlandı. Olguların ailelerinden yazılı ve sözlü onam alındı. Şiddetli hepatik, renal ve gastrointestinal disfonksiyonu, güç entübasyon riski, kullanılan ilaçlara karşı aşırı duyarlıIığı, aktif sistemik hastalığı, kontrolsüz hipertansiyonu, kafa içi basınç artışı, metabolik bozukluğu veya elektrolit dengesizliği, aşırı dehidratasyonu veya malnutrisyonu olan olgular, acil vakalar çalışma dışı bırakıldı.

Daha önceden anestezi polikliniğinde preanestezik değerlendirilmesi yapılan tüm çocukların sedasyon işlemi öncesinde 2 saate kadar berrak sıvılar almasına izin verildi. 36 aydan büyüklerin 8 saat, 12-36 aylık olanların 6 saat öncesine kadar süt dahil gıda almalarına izin verildi. IV kanülasyon işlemden 1 saat önce premedikasyon odasında 22-24 gauge kanül ile deneyimli bir anestezist tarafından yapıldı.

IV kanülasyon sonrasında MR ünitesine alınan olguların bazal değerlerimizi oluşturacak olan başlangıç sistolik-diyastolik kan basınçları (SKB,DKB), kalp tepe atımı (KTA), oksijen satürasyonu (SPO2) değerleri kayıt edildi. Tüm olgulara oksijen maskesi ile 2 It/dakika oksijen verildi.

Randomizasyon için olgular, kapalı, opak zarf usulüyle rastgele iki gruptan birine dahil edildi;

Grup 1; Midazolam iv $0.1 \mathrm{mg} / \mathrm{kg}+$ Ketamin iv 2 $\mathrm{mg} / \mathrm{kg}$ indüksiyon, idamede ek doz ketamin $0.5 \mathrm{mg} /$ kg Grup 2; Tiopental iv $3 \mathrm{mg} / \mathrm{kg}$ indüksiyon, idamede gereğinde ek doz $1 \mathrm{mg} / \mathrm{kg}$, uygulanacak şekilde 2 gruba ayrıldı.

Sedasyon düzeyini belirlemede University of Michigan Sedation Scale (UMSS) (Tablo 1) kullanıldı. UMSS 3 ve üzeri olması yeterli sedasyon düzeyi olarak kabul edilip hastalar, MRG'ye verildi. Her iki grupta da yeterli sedasyon düzeyi (UMSS'ye göre 3 puan) sağlanamazsa veya işlem sırasında uyanıklıkta artış olması durumunda ek dozların yapılması planlandı.

SKB, DKB, KTA, SpO2 ve solunum sayısı ilaç verilmeden önce, MRG odasında ilaç verildikten sonra, işlem sonunda, derlenme sırasında yapıldı.

\section{Tablo 1: University of Michigan Sedation Scale (UMSS)}

0: Tamamen uyanık

1: Uykulu(Minimal sedatize)

2: Hafif uyaranla uyandırılabiliyor(Orta derece sedatize)

3: Fiziksel uyaranla uyandırılabiliyor(Derin sedatize)

4: Hasta uyandırılamıyor. 
Tablo 2: 3 puanlı derece

1: Mükemmel, (Çekim kusursuz)

2: Küçük kusur (Çekim tamamlandı)

3: Kötü (Çekim tamamlanamadı)

Tablo 3: Aile memnuniyeti 4 puanlı ölçek

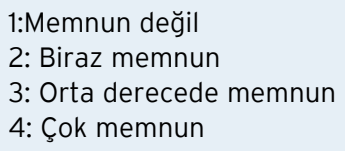

KTA ve SpO2 işlem başlangıcından itibaren $5 \mathrm{dk}$ aralıklarla sürekli takip edildi.

Illk ilaç verildikten sonra UMSS 3 sedasyon düzeyine ulaşana kadar geçen süre indüksiyon süresi olarak, MRG odasında geçen süre işlem süresi olarak, işlem bitimi ile sedasyon düzeyi 1 puan olana kadar geçen süre derlenme süresi olarak, istenen düzeyde (3 puan) sedasyon ile ilaç verilmeden önceki sedasyon düzeyine (0 puan) gelene kadarki süre toplam sedasyon süresi olarak kaydedildi. Sedasyon düzeyi takibi $5 \mathrm{dk}$ aralıklarla yapıldı. Kullanılan toplam ilaç miktarı işlem sonunda kaydedildi. MRG'yi yapan radyoloji teknisyeni tarafından çekim kalitesi 1-3 arasında değişen sözel skorlama sistemi ile değerlendirildi (Tablo 2).

İşlem sırasında karşılaşılabilecek; sedasyonun başarısız olması, apne, desatürasyon (orta düzeyde $\mathrm{SpO} 2<\% 95$, şiddetli düzeyde SpO2 <\%90), paradoksal reaksiyon (huzursuzluk, mücadelecilik, ajitasyonun devamı), allerjik reaksiyon, bradikardi, hipotansiyon (başlangıç değerinin \%20 altı) kaydedildi. Desatürasyon durumunda infüzyon hızının azaltılıp, gerekirse çene asma, maske ile solunum desteği yapılması planlandı. Bradikardi durumunda, 0,01 $\mathrm{mg} / \mathrm{kg}$ atropin uygulanması planlandı.

MRG işleminden sonra ebeveynlerin tüm işlem boyunca uygulananlardan memnuniyeti 4 puanlı sözel skala ile değerlendirildi (Tablo 3).

Hastalar uyandırma ünitesinde 2 saat takip edildi. Takiplerinde sorun olmayan hastalar tavsiyelerle evlerine taburcu edildi.

\section{Verilerin İstatistiksel Analizi}

Araştırmada elde edilen verilerin analizi SPSS 18 istatistiksel paket programı ile yapıldı. Tanımlayıcı istatistikler sürekli değişkenler için ortalama \pm standart sapma şeklinde, nominal değişkenlerde ise olgu sayısı ve (\%) olarak gösterildi. Sürekli değişkenlerde bağımsız gruplar arasında ortalamalar yönünden farkın istatiksel olarak anlamlılığını belirlemek için Student's t kullanıldı. Tüm testlerde ortalamalar arasında farklılığın önemi, eşit varyans varsayımı altında hesaplanan 2 yönlü $p$ değeri 0.05 ten küçük olduğunda istatistiksel olarak anlamlı kabul edildi. Varyans homojenliği varsayımı ise Levene testi ile sınanmış ve $p$ değerleri 0.05 'ten büyük olduğundan grup varyanslarının homojen olduğu sonucuna varılmıştır.Her yanıt değişkeni için güven aralıkları ilgili grupların örneklem ortalamalarındaki farkın \%95 olasılıkla Student's t testine göre alt ve üst sınırlarını belirlenmiştir.

\section{BULGULAR}

Çalışmamızda rastgele iki gruba ayırdığımız 40 hastadan Grup 1'de yer alan 20'sine midazolam+ ketamin kombinasyonu, Grup 2'de yer alan diğer 20 hastaya da tiyopental i.v yoldan uygulanarak MRG çekim işlemi gerçekleştirildi. Grup 1'deki hastalardan 11'i kız, 9'u erkek iken Grup 2'de yer alan hastaların 13'ü kız, 7'si erkek idi. Hastaların yaş dağılımı 4 ay ile 8yaş arasında değişmekteydi. Grupların yaş ve ağırlık dağılımları arasında istatistiksel olarak anlamlı fark bulunmamıştır (Tablo 4).

Tablo 4: Grupların yaş (ay), ağırlık(kg), indüksiyon süresi (sn), Toplam sedasyon süresi (dk), derlenme süresi (dk) ve MR çekim süresi (dk). (Ort \pm SS)

\begin{tabular}{lccccc}
\hline & Grup1 & Grup2 & p & Alt limit & Üst limit \\
\hline Yaş (ay) & 25,2 & 28,75 & 0,572 & $-16,0387$ & 8,988697 \\
Ağırlık(kg) & 14,95 & 12,08 & 0,115 & $-0,73156$ & 6,481556 \\
İndüksiyon Süresi (sn) & $93,15 \pm 37,03$ & $57,5 \pm 25,77$ & 0,001 & 15,22585 & 56,07415 \\
Toplam Sedasyon Süresi & $65 \pm 25,13$ & $46,75 \pm 28,67$ & 0,035 & 1,336359 & 35,16364 \\
Derlenme Süresi & $37,55 \pm 17,29$ & $28,4 \pm 57,77$ & 0,038 & 0,543996 & 17,656
\end{tabular}


Tablo 5: Kalp Tepe Atımı Değişimleri

\begin{tabular}{lccccc}
\hline & & \multicolumn{3}{c}{ Kalp Tepe Atımı } \\
Süre(dk) & Grup 1 (ortalama) \pm SS & Grup 2 (ortalama) \pm SS & p & Alt Limit & Üst limit \\
\hline 0 & $112,44 \pm 20,656$ & $115,8 \pm 15,463$ & 0,559 & $-15,08$ & 8,28 \\
5 & $110,25 \pm 20,486$ & $112,25 \pm 13,653$ & 0,718 & $-13,144$ & 9,144 \\
10 & $113,35 \pm 21,397$ & $109,9 \pm 13,676$ & 0,547 & $-8,045$ & 14,945 \\
15 & $113,6 \pm 20,877$ & $109,05 \pm 13,145$ & 0,415 & $-6,617$ & 15,717 \\
20 & $113,8 \pm 22,869$ & $110,8 \pm 14,962$ & 0,626 & $-9,371$ & 15,371 \\
30 & $113,85 \pm 21,389$ & $110,25 \pm 12,744$ & 0,522 & $-7,671$ & 14,871 \\
40 & $113,55 \pm 21,165$ & $110,5 \pm 12,589$ & 0,583 & $-8,097$ & 14,197 \\
50 & $113,1 \pm 20,741$ & $112 \pm 11,689$ & 0,837 & $-9,677$ & 1,877 \\
60 & $113,3 \pm 21,436$ & $112,2 \pm 12,882$ & 0,845 & $-10,221$ & 12,421 \\
90 & $112,55 \pm 21,840$ & $111,55 \pm 12,181$ & 0,859 & $-10,32$ & 12,32 \\
120 & $112,7 \pm 21,777$ & $111,65 \pm 12,754$ & 0,853 & $-10,374$ & 12,474
\end{tabular}
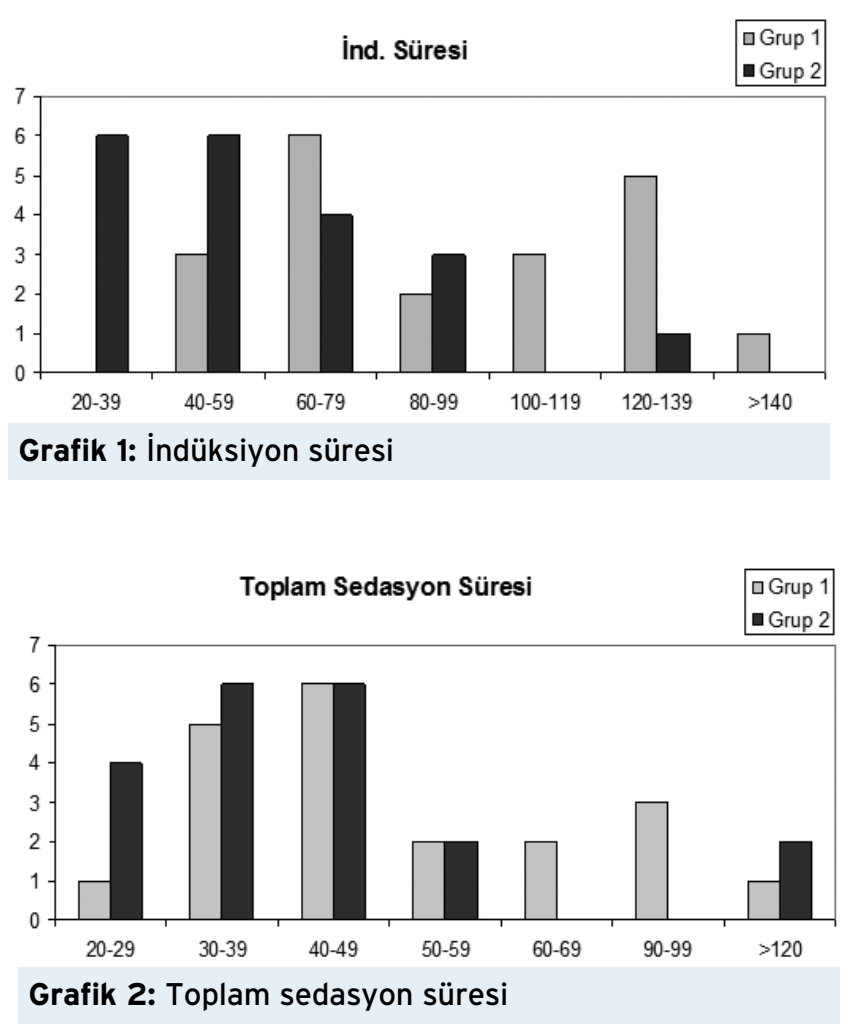

Grup 1'in indüksiyon süreleri, toplam sedasyon süreleri ve derlenme süreleri ortalamaları Grup 2 'den istatiksel olarak anlamlı oranda uzundur ( $p=0,001$, $p=0,035, p=0,038$ ) (Grafik 1,2,3, Tablo 4).

Her iki grup karşılaştırıldığında KTA, SKB, DKB ve SpO2 dağılımları arasında tüm zamanlarda istatiksel anlamlı farklılık tespit edilmemiştir (Tablo 5,6,7,8).

Aile memnuniyeti açısından değerlendirildiğinde, midazolam -ketamin grubunda 19 kişi çok memnun, 1 kişi ortaderece memnun olarak, tiyopental uygula-

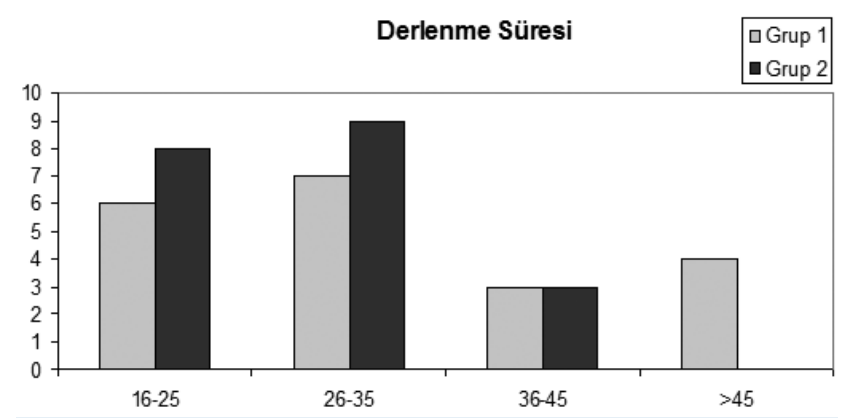

Grafik 3: Derlenme süresi

nan grupta ise 18 kişi çok memnun, 2 kişi orta derecede memnun olarak belirtti. Çekim kalitisinin değerlendirilmesinde de gruplar arasında anlamlı farklılık tespit edilmemiştir (Tablo 9). Grupların ikisinde de yan etki ile karşılaşılmamıştır.

\section{TARTIŞMA}

Ameliyathane dışı anestezi uygulamaları; kullanıIan ajanların etkileri, ortam koşulları, cihaz ve ekipman özellikleri sebebiyle, gerek uygulayıcı gerekse hasta açısından, ameliyathane koşullarına göre daha riskli girişimler olarak kabul görmektedir. Günübirlik anestezide temel ilke hastaların anestezi ve cerrahi girişimi izleyen erken saatlerde fizik ve mental aktiviteleri yeterli olarak hastaneden ayrılmalarının sağlanmasıdır. Bu durum anestezistleri güvenli, etkin ve erken ambulasyon sağlayan yöntemleri aramaya yöneltmiştir. Radyolojik görüntüleme tetkikleri arasında yer alan MRG, sıklıkla başvurulan, doğru değerlendirme, tanı ve gerekli yönlendirme açısından 
Tablo 6: Sistolik Kan Basıncı Değişimleri

\begin{tabular}{lccccc}
\hline & & \multicolumn{3}{c}{ Sistolik Kan Basıncı } \\
Süre(dk) & Grup 1 (ortalama) $\mathbf{S S}$ & Grup 2 (ortalama) \pm SS & $\mathbf{p}$ & Alt Limit & Üst limit \\
\hline 0 & $97,15 \pm 11,847$ & $96,4 \pm 11,043$ & 0,837 & $-6,581$ & 8,081 \\
5 & $95,2 \pm 11,976$ & $93,7 \pm 10,815$ & 0,680 & $-5,805$ & 8,805 \\
10 & $95,7 \pm 13,754$ & $93,1 \pm 10,657$ & 0,508 & $-5,276$ & 10,476 \\
15 & $96,4 \pm 13,153$ & $92,25 \pm 9,290$ & 0,256 & $-3,139$ & 11,439 \\
20 & $94,3 \pm 14,978$ & $92,8 \pm 9,785$ & 0,710 & $-6,599$ & 7,599 \\
30 & $93,1 \pm 14,257$ & $93,5 \pm 10,107$ & 0,919 & $-8,311$ & 7,511 \\
40 & $92,8 \pm 12,425$ & $94,15 \pm 9,477$ & 0,701 & $-8,424$ & 5,724 \\
50 & $94,05 \pm 11,989$ & $94,2 \pm 10,066$ & 0,966 & $-7,236$ & 6,936 \\
60 & $94,5 \pm 12,976$ & $94,65 \pm 10,975$ & 0,969 & $-7,843$ & 7,543 \\
90 & $94,3 \pm 12,566$ & $94,95 \pm 10,262$ & 0,859 & $-7,994$ & 6,694 \\
120 & $95,55 \pm 12,028$ & $96,3 \pm 10,388$ & 0,834 & $-7,944$ & 6,444
\end{tabular}

Tablo 7: Diyastolik Kan Basıncı Değişimleri

\begin{tabular}{lccccc}
\hline & & & Diyastolik Kan Basıncı & \\
Süre(dk) & Grup 1 (ortalama) \pm SS & Grup 2 (ortalama) \pm SS & p & Alt Limit & Üst limit \\
\hline 0 & $56,95 \pm 10,185$ & $59,95 \pm 8,088$ & 0,309 & $-8,887$ & 2,887 \\
5 & $55,4 \pm 9,659$ & $54,2 \pm 7,811$ & 0,668 & $-4,423$ & $-4,273$ \\
10 & $56,5 \pm 10,303$ & $55,25 \pm 6,536$ & 0,649 & $-4,826$ & 4,773 \\
15 & $57,5 \pm 8,691$ & $57,5 \pm 6,177$ & 1 & $-6,246$ & 4,046 \\
20 & $56,3 \pm 9,056$ & $57,4 \pm 6,870$ & 0,668 & $-8,877$ & 0,877 \\
30 & $53,4 \pm 8,344$ & $57,4 \pm 6,816$ & 0,105 & $-9,248$ & 0,048 \\
40 & $54,4 \pm 7,708$ & $59 \pm 6,782$ & 0,052 & $-10,221$ & 0,021 \\
50 & $54 \pm 8,284$ & $59,1 \pm 7,704$ & 0,051 & $-10,573$ & 0,873 \\
60 & $53,8 \pm 59,320$ & $58,7 \pm 8,542$ & 0,094 & $-6,556$ & 3,056 \\
90 & $56,6 \pm 8,249$ & $58,35 \pm 6,683$ & 0,466 & $-6,77$ & 5,27
\end{tabular}

Tablo 8: Oksijen Satürasyonu Değişimi

\begin{tabular}{lccccc}
\hline & & \multicolumn{3}{c}{ Oksijen Satürasyonu } \\
Süre(dk) & Grup 1 (ortalama) \pm SS & Grup 2 (ortalama) \pm SS & p & Alt Limit & Üst limit \\
\hline 0 & $98,55 \pm 0,759$ & $98,55 \pm 0,887$ & 1 & $-0,529$ & 0,529 \\
5 & $98,45 \pm 2,395$ & $98,85 \pm 0,875$ & 0,487 & $-1,554$ & 0,754 \\
10 & $99,05 \pm 0,686$ & $99,05 \pm 0,686$ & 1 & $-0,439$ & 0,439 \\
15 & $99,05 \pm 0,686$ & $99,05 \pm 0,686$ & 1 & $-0,439$ & 0,439 \\
20 & $98,95 \pm 0,510$ & $98,95 \pm 0,394$ & 1 & $-0,292$ & 0,292 \\
30 & $98,80 \pm 0,696$ & $98,8 \pm 0,523$ & $-0,394$ & 0,394 \\
40 & $98,85 \pm 0,671$ & $98,55 \pm 0,605$ & 0,146 & $-0,109$ & 0,709 \\
50 & $98,8 \pm 0,523$ & $98,6 \pm 0,598$ & 0,267 & $-0,16$ & 0,56 \\
60 & $98,65 \pm 0,587$ & $98,6 \pm 0,598$ & 0,791 & $-0,329$ & 0,429 \\
90 & $99,05 \pm 0,686$ & $98,6 \pm 0,598$ & 0,033 & 0,038 & 0,862 \\
120 & $98,75 \pm 0,550$ & $98,6 \pm 0,598$ & 0,414 & $-0,218$ & 0,518
\end{tabular}

Tablo 9: Grupların aile memnuniyeti ve çekim kalitesi (n)

\begin{tabular}{lcc}
\hline & Grup T & Grup MK \\
\hline Aile memnuniyeti & 0 & 0 \\
1-Hiç memnun değil & 0 & 0 \\
2-Biraz memnun & 1 & 2 \\
3-Orta derecede memnun & 19 & 18 \\
4-Çok memnun & \multicolumn{2}{|c}{} \\
Çekim kalitesi & 18 & 17 \\
1-Mükemmel & 2 & 3 \\
2-Küçük kusur & 0 & 0
\end{tabular}


çekim işlemi sırasında mutlak hareketsizlik gerektiren bir uygulamadır (7).

$M R G^{\prime}$ de sedasyon için tiyopental, propofol, ketamin, midazolam, etomidat, fentanil gibi ajanlar kullanılır (7). Okul öncesi çocuklarda en sık kullanılan ilaç olan midazolam, sedasyon, anksiyoliz ve anterograd amnezi sağlar (8).

Biz de çalışmamızda MRG tetkiki için anestezi uygulanacak pediatrik olgularda midazolam-ketamin kombinasyonu ile tiopentalin anestezi kalitesi, girişim sırasındaki konfor ve derlenme üzerine etkilerinin karşılaştırılmasını amaçladık. Literatürde, tiopental ve ketamini farklı ajanlarla karşılaştıran çalışmalar mevcut olmasına karşın, iki ajanın MRG'de kullanımına ilişkin karşılaştırmalı çalışmaya rastlanmamıştır.

Ketamin hızla derin sedasyon ve analjezi sağlayan, yavaş verildiği takdirde solunumu ve hava yolu reflekslerini koruyan, kan basıncı ve kalp hızında hafif yükselme yapan bir ilaçtır. Yüksek dozları ile genel anestezi sağlanır, ağrılı uyarana yanıt olmaz ama solunum devam eder. Bu avantajları sebebiyle, günübirlik anestezide sıklıkla tercih edilen bir ajandır (4).

Acworth ve ark. ile Dachs ve Innes ketamine midazolam eklenmesiyle, hoş olmayan rüyalar, halüsinasyonlar gibi ketamine bağlı istenmeyen etkilerin azaltıldığını ileri sürmüşlerdir $(9,10)$. Biz de bu sebeple, ketamini midozolam ile kombine ederek kullandık.

Özalevli ve ark.'nın 2-2,5 mg. kg iv bolus, ardından $100 \mu \mathrm{g} . \mathrm{kg}$ infüzyon propofolle, 2-2,5 mg kg iv bolus ardından aralıklı uygulanan iv 0,5 mg kg ketamini karşılaştırarak yaptıkları çalışmada, propofol grubunda hem anestezi uygulaması öncesi değerlerine göre hem de ketamin grubuna göre kan basınçları anlamlı derecede düşük seyretmiştir. Ketaminin kardiyovasküler sisteme yan etkileri minimal olarak bulmuşlardır. Ancak, propofol ile derlenme daha hızlı olmuştur (11). Özdamar ve arkadaşları da, MRG'de propofol infüzyonu ile $1,5 \mathrm{mg} / \mathrm{kg}$ dozunda ketamin kullanımını karşılaştırmışlar ve propofol ile daha derin sedasyon, daha hızlı uyanma, ketamin grubunda ise kardiyovasküler ve solunumsal yan etkiler daha az görülmüştür (12).

Tiyopental, oldukça hızlı indüksiyon sağlayan ve pediatrik anestezi uygulamalarında tercih edilen bir ajandır. Kardiyovasküler sistemi ve solunumu baskılayabilmektedir6.Charles M. Glasier ve ark. Tiyopental sodyumu MR çekilecek çocuklarda rektal yoldan uygulamışlar ve hastaların \%96'nda başarılı bir sedasyon sağlamışlardır (13).

Priti G. Dalal ve arkadaşlarının yaptığı çalışmada yenidoğanlara MRG işlemi esnasında sedasyon uygulanmış 258 yenidoğan çalışmaya alınmıştır. Çocuklara premedikasyon olarak oral midazolam, damaryolu açıldıktan sonra da iv midazolam yapılmıştır. Rastgele 3 gruba ayrılan çocukların 102 tanesine oral chloral hydrate, 67 tanesine pentobarbital iv bolus olarak, 68 tanesine de propofol iv infüzyon şeklinde uygulanmıştır. Kardiyorespiratuar olaylar en az chloral hydrate grubunda görülmüş, hastanın MRG çekimi için hazır hale gelme süresi en kısa propofol grubunda bulunmuş, taburculuk süresi en uzun pentobarbital grubunda, en kısa ise propofol grubunda bulunmuştur. Çekim esnasında hareketlilik pentobarbital grubunda \%12,2 ve propofol grubunda \%1,4 oranında bulunmuştur (14). Malviya ve arkadaşları, $M R G$ 'de pentobarbitali kloralhidrat ile karşılaştırmışlar, pentobarbital grubunda indüksiyon daha hızlı, ek sedatif ajan ihtiyacı dah az bulunmuş, ancak derlenme daha yavaş olmuştur (15).

Pershad ve arkadaşları yaptıkları çalışmada MRG çekimi uygulanacak 1 ile 17 yaş arası toplam 60 olguda propofol infüzyonunu, pentobarbital, midozolam ve fentanil sedasyonu ile karşılaştırmışlar, derlenme zamanı, indüksiyon zamanı, toplam sedasyon zamanı, görüntülemenin kalitesi, sekansların tekrarlanması, hasta yakınlarının memnuniyeti ve sedasyon öncesi fiziksel duruma dönme zamanı gibi parametreleri propofol grubunda belirgin kısa bulunmuştur. Her iki grupta da belirgin bir yan etki ve sedasyonda başarısızlık görülmemiştir (16). Türker ve ark, propofol infüzyonu ile tiyopentalin bolus uygulamasını karşılaştırdıklarında, propofol uygulanan olgularda daha erken derlenme ve düşük yan etki insidansı elde edilmiştir. Bu bulgular, pediyatrik BT uygulamalarında sedasyon sağlamak amacıyla uygulanan propofol infüzyonunun, rutinde kullanılan tiyopental bolus uygulamasına etkin ve güvenli bir alternatif olabileceğini göstermiştir (17).

Kain ve arkadaşlarının yaptığı çalışmada MRG 
çekim işlemi uygulanan 58 çocukta propofol ve tiyopental anestezisini maliyet analizi açısından karşılaştırılmıştır. Propofol grubunda derlenme zamanı (19 dak) tiyopental sodyum grubundan (35 dak) belirgin derecede düşük çıkmıştır. Morbidite ve teknik yeterlilik açısından farklılık görülmemiştir. Ancak, tiyopental anestezisinin maliyeti daha düşük çıkmıştır (18). Bloomfield ve arkadaşları, propofol ile uygulanan sedasyonda tiyopentale göre daha fazla kardiyak ve solunumsal depresyon görüldügünü, bu sebeple propofol sedasyonunun sürekli anestezist gözetiminde ve yakın takiple uygulanabileceğini söylemişlerdir (19). Mallory ve arkadaşlarının 7079 MRG yapılan pediatrik olguda yaptıkları çalışmada propofolün daha etkin anestezi sağladığı, propofol grubunda daha fazla apne görülmesine rağmen bunun istatiksel olarak tiyopentalden farklı olmadığı vurgulanmıştır (20).

Öztürk ve ark. MR uygulaması sırasında olgulara sedasyon amacıyla anestezik ajan olarak midazolam $0.1 \mathrm{mg} . \mathrm{kg}$ iv, ketamin 0,5-1 mg.kg iv, propofol 2-3 mg.kg iv veya fentanil 0.5-2 $\mu$ g. kg dozlarında kullanmışlar ve tüm vakalara sedasyon sağlanmış, genel anestezi gerekliliği olmamıştır. Sedasyon sırasında toplam 1458 olgunun 168'inde minör komplikasyonlar; bradikardi (45), desatürasyon (98) ve uzamış sedasyon (22) ile karşılaşılmışlardır (21).

Malviya ve ark. (6) çocuklarda tanısal işlemler için yapılan sedasyonlarda komplikasyon oranının \%20.1 olduğu ve bunların büyük çoğunluğunun (\%5.5) solunum komplikasyonlarının oluşturduğu rapor edilmektedir (22). Malviya ve ark. diğer çalışmaların-

\section{KAYNAKLAR}

1. Formica D, Silvestri S. Biological effects of exposure to magnetic resonance imaging: an overview. Biomed Eng Online 2004;3:11.

2. Peden CJ, Menon DK, Hall AS, Sargentoni J, Whitwam JG. Magnetic resonance for the anaesthetist Part II. Anaesthesia and monitoring in MR units. Anaesthesia 1992;47(6):508-17.

3. Gooden CK. Anesthesia for magnetic resonance imaging. Curr Opin Anaesthesiol 2004;17(4):339-42.

4. McCarty EC, Mencio GA, Walker LA, Green NE. Ketamine sedation for the reduction of children's fractures in the emergency department. J Bone Joint Surg Am 2000;82-A(7):912-8.

5. Howes MC. Ketamine for paediatric sedation/analgesia in the emergency department. Emerg Med J 2004;21(3):275-80.

6. Cravero JP, Blike GT. Review of pediatric sedation. Anesth Analg 2004;99(5):1355-1364.

7. Starkey E, Sammons HM. Sedation for radiological imaging. Arch Dis Child Educ Pract Ed 2011;96(3):101-6. da MRG veya CT işlemleri için sedasyon verilirken en sık karşılaşılan istenmeyen durumun \%13.1'lik oranla sedasyon yetersizliği olduğu tespit edilmiş ve bunların \%3.7 sinde işleme son verilmek zorunda kalınmış. İşleme son verilen çocukların bir kısmına genel anestezi altında MRG veya CT tekrarlanmışken geri kalan olgulara sedasyon uygulanarak işlem tekrarlanmıştır (23). Biz çalışmamızda yetersiz sedasyon, yada diğer yan etkilerle karşılaşmadık.

Biz çalışmamızda midazolam-ketamin verilen grupla tiyopental verilen grubu karşılaştırdığımızda; her iki grubunda KTA, SKB, DKB ve SPO2 oksijen saturasyonuna etkilerini benzer bulduk. Her iki gruptada bradikardi, hipotansiyon ve oksijen desatürasyonu gözlenmedi. Bu yönden her iki gurubundan güvenli sedasyon sağladığı kanaatine vardık. Her iki grupta da MR çekimi için yeterli sedasyon düzeyine ulaşıldı. Midazolam-ketamin grubunun yeterli sedasyon düzeyine ulaşmasının daha uzun sürdügünü ve sedasyon süresinin daha uzun olduğunu bulduk. Tiyopental uygulanan grupta ise yeterli sedasyon düzeyine ulaşma daha kısa olurken, midazolamketamin kombinasyonu uygulanan grupla kısyaslandığında derlenme süresininde daha kısa olduğu sonucuna ulaştık.

Sonuç olarak; tiyopental MRG'de midozolam ve ketamin kombinasyonuna alternatif olarak güvenle kullanılabilir. Çekim kalitesinin iyi olması, anestezi indüksiyon süresi ve derlenme süresinin kısa olması, tiyopentali MRG'de daha etkin bir anestezik ajan haline getirmektedir.

8. Pandit UA, Collier PJ, Malviya S, Voepel-Lewis T, Wagner D, Siewert MJ. Oral transmucosal midazolam premedication for preschool children. Can JAnaesth 2001;48(2):191-5.

9. Acworth JP, Purdie D, Clark RC. Intravenous keÂAtamine plus midazolam is superior to intranasal midazolam for emergency paediatric proceduÂحral sedation. Emerg Med J 2001;18(1):3945.

10. Dachs RJ, Innes GM. Intravenous ketamine seÂनdation of pediatric patients in the emergency department. Ann Emerg Med 1997;29(1):146-50.

11. Özalevli $M$, Ünlügenç $H$, Gündüz $M$, Çetin $T$, Özcengiz D. Çocuklarda Manyetik Rezonans Görüntülemede Propofol ile Ketaminin Karşılaştırmalı Değerlendirilmesi. Türkiye Klinikleri J Anest Reanim 2005;3:7-14. 
12. Dilek Özdamar, Tülay Hoşten, Yavuz Gürkan, Kamil Toker, Mine Solak. Çocuklarda Magnetik Rezonans Görüntüleme Sedasyonunda Propofol ve Ketamin. Türk Anest Rean Der Derg 2010; 38(2):91-100.

13. Glasier CM, Stark JE, Brown R, James CA, Allison JW. Rectal thiopental sodium for sedation of pediatric patients undergoing $M R$ and other imaging studies. AJNR Am J Neuroradiol 1995;16(1):111-4.

14. Dalal PG, Murray D, Cox T, McAllister J, Snider R. Sedation and anesthesia protocols used for magnetic resonance imaging studies in infants: provider and pharmacologic considerations. Anesth Analg 2006;103(4):863-8.

15. Malviya S, Voepel-Lewis T, Tait AR, Reynolds PI, Gujar SK, Gebarski SS, Petter Eldevik O. Pentobarbital vs chloral hydrate for sedation of children undergoing MRI: efficacy and recovery characteristics.Paediatr Anaesth 2004;14(7):589-95.

16. Pershad J, Wan J, Anghlescu DL. Comparison of propofol with pentobarbital/midazolam/fentanyl sedation for magnetic resonance imaging of brain in children. Pediatrics 2007; 120(3):e629-636.

17. Gürkan Türker, Alp Gurbet, Adnan Tüfek, Emre Güler, Berin Özcan Pediyatrik Olgularda Bilgisayarlı Tomografi Uygulamalarında Intravenöz Sedasyon için Tiyopental ile Propofolün Karşılaştırılması. Türk Anest Rean Der Derg 2004;32:33-9.
18. Kain NZ, Gaal DJ, Kain TS, Jaeger DD, Rimar S. A first pass cost analysis of propofol versus barbiturates for children undergoing magnetic resonance imaging. Anesth Analg 1994;79(6):11021106.

19. Bloomfield EL, Masaryk TJ, Caplin A, Obuchowski NA, Schubert A, Hayden J, Ebrahim ZY, Ruggieri PM, Goske MJ, Ross JS. Intravenous sedation for MR imaging of the brain and spine in children: pentobarbital versus propofol. Radiology 1993;186(1):93-97.

20. Mallory MD, Baxter AL, Kost SI, Pediatric Sedation Research Consortium. Propofol vs pentobarbital for sedation of children undergoing magnetic resonance imaging: results from the Pediatric Sedation Research Consortium. Paediatr Anaesth 2009; 19(6):601-1.

21. Erdoğan Öztürk, Aytaç Yücel, Zekine Begeç, Feray Akgül Erdil, Kadir Demir, M. Özcan Ersoy. Manyetik Rezonans Görüntüleme Ünitesindeki Pediyatrik Olgularda Anestezi Deneyimlerimiz. Inönü Üniver Tıp Fak Derg 2008;15(4):239-43.

22. Malviya S, Voepel-Lewis T, Tait AR. Adverse events and risk factors associated with the sedation of children by nonanesthesiologist. Anesth Analg 1997; 85(6): 1207-1213.

23. Malviya S, Voepel-Lewis T, Eldevik OP, Rockwell DT, Wong JH, Tait AR. Sedation and general anaesthesia in children ndergoing MRI and CT; adverse events and outcomes. Br J Anaesth 2000; 84(6):743-8. 